\title{
Article
}

\section{Celebrations amongst challenges: Considering the past, present and future of the qualitative methods in psychology section of the British Psychology Society}

Riley, Sarah, Brooks, Joanna, Goodman, Simon, Cahill, Sharon, Branney, Peter, Treharne, Gareth J. and Sullivan, Cath

Available at http://clok.uclan.ac.uk/28728/

Riley, Sarah, Brooks, Joanna, Goodman, Simon, Cahill, Sharon, Branney, Peter, Treharne, Gareth J. and Sullivan, Cath ORCID: 0000-0001-5417-8945 (2019) Celebrations amongst challenges: Considering the past, present and future of the qualitative methods in psychology section of the British Psychology Society. Qualitative Research in Psychology, 16 (3). pp. 464-482. ISSN 14780887

It is advisable to refer to the publisher's version if you intend to cite from the work. http://dx.doi.org/10.1080/14780887.2019.1605275

For more information about UCLan's research in this area go to http://www.uclan.ac.uk/researchgroups/ and search for <name of research Group>.

For information about Research generally at UCLan please go to http://www.uclan.ac.uk/research/

All outputs in CLoK are protected by Intellectual Property Rights law, including Copyright law. Copyright, IPR and Moral Rights for the works on this site are retained by the individual authors and/or other copyright owners. Terms and conditions for use of this material are defined in the policies page. 
UK Qualitative Methods in Psychology (QMiP)

Title: Celebrations amongst challenges: Considering the past, present and future of the Qualitative Methods in Psychology (QMiP) section of the British Psychological Society

Authors: Sarah Riley, Aberystwyth University; Joanna Brooks, University of Manchester; Simon

Goodman, Coventry University; Sharon Cahill, University of East London; Peter Branney, Bradford University; Gareth J. Treharne, University of Otago; and Cath Sullivan, University of Central Lancashire.

Corresponding author: Jo Brooks, Joanna.Brooks@manchester.ac.uk

This is an Author's Original Manuscript of a paper that has been accepted for publication in Qualitative Research in Psychology, published by Taylor Francis. 
Celebrations amongst challenges: Considering the past, present and future of the Qualitative Methods in Psychology (QMiP) Section of the British Psychology Society

\begin{abstract}
This article summarises the standpoint of the Qualitative Methods in Psychology Section of the British Psychological Society regarding the current position of qualitative research in psychology in the UK. The article is in three parts. Part one documents the historical development of the section, outlining its rationale, remit and current activities. These activities aim to champion and develop qualitative methods in psychology, supporting high quality work regardless of epistemological or ontological position. Part two considers the current context of our work, describing how qualitative methods are valued in the UK, but also how this recognition is undermined, particularly through the operationalisation of our national research assessment (the Research Excellence Framework). We also consider the challenges that Open Science poses for qualitive researchers. Part three highlights some of the significant contributions UK-based qualitative researchers have made to psychology, with a particular focus on feminist-informed research, discourse analysis, and interpretative phenomenological analysis; before pointing to future exciting possibilities based on research exploring the affordances of digital technologies and innovative synthesising across epistemologies and disciplinary boundaries.
\end{abstract}

Key words: British Psychological Society, QMiP, qualitative methods, UK, Research Excellence Framework, Open Science 


\section{Introduction}

In this article we review qualitative research in psychology in the UK. To do so, we document the historical development of the Qualitative Methods in Psychology (QMiP) Section of the British Psychology Society (BPS), before considering the contemporary context of qualitative research in UK psychology.

\subsection{The development of QMiP}

QMiP formed in 2005 against a backdrop of increased use of qualitative methods in psychological research in the UK (Madill, 2015). In the latter half of the $20^{\text {th }}$ Century a range of individual and institutional actions contributed to this increase, including those responding to the 'crisis of representation' informed by separate and interconnecting poststructuralist, Marxist and feminist movements (whose concerns were around ethics, representation, and knowledge production) (Henriques, Hollway, Urwin, Venn \& Walkerdine, 1984). Another important contribution came from phenomenological and humanist research that prioritised a focus on understanding lived experience (Smith, Flowers \& Larkin, 2009).

What these different standpoints shared was a critique of the dominant positivist approach for failing to recognise the centrality of interpretation in the psychological research endeavour. For example, those informed by the crisis of representation argued that science did not create objective knowledge, but knowledge produced from a partial (often white male-norm) standpoint that had ethical and political implications; while those inspired by phenomenological philosophies argued that psychology needed to start with how people interpret their world (Ashworth, 2008; Burman, 1990). These ideas were enabled through cross disciplinary fertilisation (such as from the Sociology of Scientific Knowledge, and especially resonated with social psychologists seeking to do new ways of psychological research 'beyond attitudes and behaviour' by 'changing the subject' (Henriques et 
UK Qualitative Methods in Psychology (QMiP)

al., 1984; Potter \& Wetherell, 1987). And in their doubts about the capacity of positivist research (and their associated quantitative methods) to illuminate the meaning and context that they saw as a defining part of human social behaviour, many of these texts promoted the use of qualitative methods for producing in-depth and contextually sensitive knowledge (Sullivan and Forrester, 2018).

As they established academic careers, researchers using these ideas produced more routes for qualitative methods to be disseminated and recognised, hosting conferences, founding journals such as Feminism \& Psychology and Qualitative Research in Psychology (established in 1991 and 2004 by teams led by Sue Wilkinson and Brendan Gough/David Giles respectively), and even leading significant Research Council programmes that funded research using qualitative methods (e.g. Margaret Wetherell's ESRC programme) $)^{\mathrm{i}}$. Such actions enhanced the position of qualitative research in psychology, particularly in feminist, phenomenological and discursive psychology; albeit within a wider context where qualitative research remained a minority pursuit amongst academics in UK Higher Education Institutions (HEIs). Nevertheless, by 2002 qualitative methods were considered by members of the BPS to be significant enough for inclusion in the subject benchmarks of a BPS accredited Psychology degree (British Psychological Society, 2016). This meant that most UK psychology degrees now include qualitative methods in their research methods curriculum - further establishing qualitative methods in the UK.

Within this history, a small group at the 1999 18th International Human Science Research Conference suggested that a 'Section' on qualitative methods for the BPS could be proposed. The BPS has a complex structure with various sub-bodies, one group of which are called 'Sections', these are academic groups focused on specific areas of scientific and academic interest (British Psychological Society, n.d.-b). Individual members of the BPS can propose a Section, which is brought into existence if enough members vote for it. At a subsequent workshop funded by the Higher Education Academy, the group from the 1999 conference decided to submit a proposal, 
which was then supported by the membership with the name of 'Qualitative Methods in Psychology' reflecting the BPS view that 'qualitative' refers to an array of methods that can be used in many substantive areas of the discipline (Gough et al., 2002; Madill, 2015; Madill \& Todd, 2002) ${ }^{\mathrm{ii}}$. Consequently, QMiP came into being in 2005, with any member of the BPS interested in qualitative research in psychology able to join (British Psychological Society, n.d.-b). QMiP was immediately popular, and to date, it remains the largest of the BPS's sections, with over 800 members (based on internal data).

QMiP engages in activities related to raising the profile of research using qualitative methods and those conducting it; disseminating and developing research methodology; and supporting teaching qualitative methods in psychology. For example, we hold a biennial conference where we share expertise, offer training, and give awards that allow us to champion qualitative researchers (including student bursaries and contributions to the discipline awards) ${ }^{\mathrm{iii}}$. We also produce a twice yearly publication, the 'QMiP Bulletin', which addresses a range of philosophical, methodological and practical issues relevant to qualitative psychology researchers; and we offer a range of responsive training and publications produced to meet the emerging needs of our community $^{\mathrm{iv}}$. We are building international networks with organisations such as the APA's Society Qualitative Inquiry in Psychology, the International Society for Critical Health Psychology and the nascent European Qualitative Research in Psychology group; while working collaboratively within the BPS, through shared conferences and symposiums with other Sections and Divisions (Divisions being BPS groups related to professional psychological practice).

To develop qualitative methods teaching and supervision, QMiP affiliated with the UKbased Teaching Qualitative Psychology (TQP) group, enabling TQP to continue developing resources for those teaching qualitative psychology in HEIs ${ }^{\mathrm{v}}$. These resources include the qualitative methods textbooks 'Doing Qualitative Research in Psychology' (Sullivan \& Forrester, 2018) and 'Doing Your Qualitative Psychology Project' (Sullivan, Gibson \& Riley, 2012), which 
UK Qualitative Methods in Psychology (QMiP)

align with publications produced by other QMiP members e.g. 'Applied Qualitative Research in Psychology' (Brooks \& King, 2017).

QMiP currently operates as a Section of the BPS within a wider context of positive indicators for qualitative research. Qualitative research receives research council funding, and in health settings, incorporating patient views is valued by those developing policies and initiatives, so that by 2017 12.9\% of research funded by the UKs National Institute for Health's Research for Patient Benefit programme had qualitative methods as their primary method. Syntheses of qualitative research are also influencing health care interventions and services (e.g. FinfgeldConnett, 2016); the UK Medical Research Council guidance on developing complex interventions state the need for both qualitative and quantitative evidence (Craig et al, 2008); and standard operating procedures for using qualitative methods to support randomised control trials now exist (Rapport, et al., 2013). These examples demonstrate the growing understanding that presenting metrics without consideration of contextual factors or explanatory narrative is not good research practice. Other positive indicators include the number of psychology journals publishing qualitative research, including special issues showcasing qualitative research (e.g. Gough \& Deatrick, 2015). It is against this backdrop, that when launching the second edition of The SAGE Handbook of Qualitative Research in Psychology at the 2017 QMiP conference, Wendy Stainton-Rogers and Carla Willig argued that qualitative psychology had transformed and was 'moving out of defensive mode'. A claim supported by an increasing interest in the use of qualitative methods amongst students, academics and clinicians in many sub-fields of psychology, with the outcome that while radical traditions remain, qualitative methods have entered the mainstream, used for example, in a range of applied realist/positivist work.

QMiP takes an inclusive stance. We understand 'qualitative methods in psychology' as an umbrella term covering an array of diverse approaches underpinned by different ontological and epistemological positions that share interest in understanding meaning-making or social processes 
through methods that do not convert data into numbers. Our role is not to be partisan, but to support the production of high quality qualitative research across the spectrum of qualitative methods. In our definition of high quality work we include research that carefully considers its epistemological, ontological and contextualised positionality. The increase in realist work is thus welcomed, but not at the price of marginalising qualitative research using other ontological and epistemological frameworks, particularly when contemporary realist qualitative researchers are, in part, only able to have their work recognised because of the historical feminist, discursive and phenomenological work that spearheaded qualitative research in the UK.

Despite these positive indicators, Madill (2015) notes that many of the issues identified as a reason for QMiP's formation continue. These include pressure on a small number of staff to fulfil teaching requirements (when, for example, staff with qualitative specialisms do more teaching or supervision because of students' preference for qualitative methods); poor access to research funding and high impact journals; and the potential for marginalisation within psychology departments. Below, we discuss how these manifest today.

2. Current challenges and threats to qualitative psychology in the UK

Marginalisation can happen in different ways. For example, ethics committees may consider our methods unconventional (Macleod, Marx, Mnyaka, \& Treharne, 2018) or inappropriately evaluate our proposals using quantitative criteria (for example, a National Health Service ethics committee told one of us to include a 'control group' to a poststructuralist-informed interview study that sought to understand the experiences of a particular group of people). Also see Carter, Chew \& Sutton (2018), for a discussion of institutional barriers because qualitative methods do not fit simplistic models of research and clinical governance in healthcare settings.

Similarly, journal articles may be assessed by reviewers who do not fully understand the diversity of qualitative approaches and theoretical frameworks. Commonly encountered issues 
UK Qualitative Methods in Psychology (QMiP)

include the inappropriate application of positivist quality criteria or an expectation that narrow and post-positivist checklists for 'quality' qualitative research should be applied across the broad qualitative methodological spectrum (e.g. expecting data saturation even if grounded theory is not being applied or inter-rater reliability for thematic analyses). Explicit publication biases against qualitative methods are also evident, including the prestigious British Medical Journal's recent policy of rejecting qualitative studies on the grounds that they are "low priority" and "not of interest" (Greenhalgh et al., 2016). Similarly, departments where there is a persistent quantitative culture impact on the teaching of research methods in HEI psychology departments, casting doubt on whether qualitative methods are as fully integrated into the curriculum as the benchmarks might suggest (Gibson \& Sullivan, 2018; Wiggins, Gordon-Finlayson, Becker and Sullivan, 2015). Such a quantitative culture is also pervasive in the operationalisation of our national research assessment procedures, as we discuss below.

\subsection{Research Excellence Framework}

Memorably described in a 2016 issue of the QMiP Bulletin as "The Voice and the Spanish Inquisition rolled into one, with a lot more meetings" (Riley, 2016, p. 5), the UK's Research Excellence Framework (REF) is a national exercise on an approximate six year cycle, which aims to assess the quality of research undertaken at UK HEIs. REF is intended to act as a driver of research excellence, to raise the profile of UK HEI research activity, and to encourage HEIs to enhance the delivery of research-related benefits (Research Excellence Framework, 2017). Despite considerable debate regarding the extent to which REF actually achieves its stipulated aims (e.g. Brooks et al., 2018a; Greenhalgh \& Fahy, 2015; Riley, 2016; Cotton et al., 2018; Murphy, 2017), REF plays a key role in determining allocation of research funding. Being deemed 'REF-able' (that is, producing research that can be submitted to REF and rated as 'internationally excellent' or 'world leading') is essential for a standard-track academic career in the UK. 
The next REF is in 2021. It is organised into four 'panels', and each panel is further divided into 'units of assessment' (UoAs). Psychological work is expected to mostly be submitted into Panel A (Medicine, Health and Life Sciences), UoA4, 'Psychology, Psychiatry and Neuroscience'. However, in the last (2014) REF we estimate that around one third of psychologists entered into the REF were submitted to another UoA, including 'Professions Allied to Medicine', 'Communication, Culture and Media Studies', and 'Social Work and Social Policy' (Brooks et al., 2018).

QMiP and other BPS Sections and committees have worked to identify the reasoning behind who was submitted and where. Much of this work is unpublished, but points to a historical legacy of qualitative work being rated poorly in previous research assessments making risk adverse HEIs concerned not to make that mistake again. Often, the rationale for HEIs submitting psychologists using qualitative methods into other units was the expectation that the reviewers on the Psychology panel would rate qualitative work lower that would reviewers in other REF panels. Psychology panels were therefore considered biased against qualitative work. We consider this bias to involve unfair evaluations, such as inappropriately reviewing of qualitative work against quality criteria for quantitative methods. For example, 'an admired dataset' is one of the valued criteria, which is often interpreted in terms of size, devaluing traditionally smaller, context-focused, non-generalisable qualitative work. Such problematic positioning of qualitative methods also meant that many qualitative researchers in psychology were rendered 'un-REFable'. Since, what was not recorded in the REF submission data, but identified in subsequent surveys (e.g. by the BPS Social Psychology Section) and informal questioning, was a pattern in which those using qualitative methods were not submitted to the REF.

The outcome of such practices, is that psychologists using qualitative methods in the UK are vulnerable to being considered people who do inherently low quality research in psychology and/or who fail to bring research-supporting money into the department. This has recruitment implications that might fundamentally shape the discipline of psychology in the UK. It also has career and 
UK Qualitative Methods in Psychology (QMiP)

identity implications for those involved. At the 2017 QMiP conference, for example, delegates reflected at length on their concerns that being submitted to a different panel positioned them as not 'proper psychologists' (since those considered doing 'real' psychological research get submitted to the psychology panel) (Brooks et al, 2018a). These vulnerabilities remain, despite a range of actions taken between QMiP and the BPS, including formal contributions to national public consultation exercises on REF.

We have had some successes. For example, having the word 'qualitative' included into the descriptor of psychological research, thus making our work explicitly part of the psychology profile. But other actions were less successful. For example, none of the people QMiP suggested for the REF2021 Psychology panel in the public consultations were accepted, and to date, all the people appointed to the panel have expertise only in research underpinned by positivist epistemology ${ }^{\mathrm{vi}}$. Given that each submitted publication must be rated by two people on this panel, it is likely that HEIs will not submit psychologists using the range of social constructionist, poststructuralist and phenomenologically informed methods to this panel, concerned that they will not be rated favourably ${ }^{\text {vii }}$. This will undoubtedly intensify the 'othering' of qualitative researchers in mainstream Psychology departments including those doing feminist, discursive and phenomenological work. Further concerns were raised in a recent presentation to the BPS Research Board by the Chair of the Psychology REF review panel, when she unveiled plans to allocate larger amounts of funding to Psychology HEI REF submissions that have $75 \%$ or more publications categorised as inherently more costly (and that qualitative methods were not considered to be in this category).

Currently, our standpoint is that there is a real danger of REF distorting the discipline by effecting HEI recruitment and changing the profile of qualitative methods in psychology. If only qualitative research that is aligned with realist ontology and positivist epistemology is valued by Psychology departments because of REF, then the outcome is likely to be a 'quantification' of qualitative work with a focus on very particular forms of and approaches to qualitative analysis. The 
feminist, discursive and phenomenological work that was so central to qualitative research in the UK may once again be marginalised - at the fringe or perhaps not in psychology at all. Anecdotally, people have told us of moves, that are at least partially REF-related, to other disciplines and even other countries. Other researchers have publicly celebrated REF-related successes that they associate with moving to REF units of assessment, such as 'Communication, Culture and Media Studies'.

\subsection{Open Science}

Open Science is another system seemingly designed with the quality criteria of quantitative work as the default. Open Science was a response to a crisis in experimental psychology ${ }^{\text {viii }}$ relating to research fraud and concerns about a much broader range of questionable research practices including ignoring or incentivising bad practice, overselling, post-hoc storytelling, p-value fishing, creative use of outliers, plagiarism, non-publication and partial publication of data (Levelt, Drenth, \& Noort, 2012; Neuroskeptic, 2012; Pashler \& Wagenmakers, 2012). These concerns were crystallised in the Open Science Collaboration (2015) report that, in replicating 100 experimental studies, found a replication rate of $36 \%$ despite $97 \%$ of the original studies reporting significant effects. Such findings suggest that questionable research practices are systemic. For example, journals only consider papers for publication once the results are known, value the novel and place an emphasis on significant differences. It is no surprise then, that since 1900 , only $1.6 \%$ of publications in the 100 psychology journals with the highest impact factors used the word 'replication' (Makel, Plucker \& Hegarty, 2012).

Such concerns originally positioned Open Science as an issue for quantitative researchers. For example, the BPS had two events on this issue - Replicability and Reproducibility Debate, $26^{\text {th }}$ May 2016 and Moving Psychological Science Forward, February $2018^{\text {ix }}$ - that made no mention of qualitative methods, as the focus was on developing new procedures for better quantitative research, 
such as requiring researchers to pre-register their study and share their data and analysis (regardless of whether the hypothesis was retained or rejected).

But the drive for more accountable and transparent research created changes in funding and publishing practices that now impact on qualitative research. For example, in the UK, the Economic and Social Science Research Council now requires grant holders to deposit research outputs in open access repositories and with the expectation that anonymised raw data will be made available for reuse within three months of grant completion (Economic and Social Research Council, 2013, 2018). Wiley, who currently publish journals for the BPS, have outlined a suite of services supporting open science $^{\mathrm{x}}$, including services for archiving and sharing data and publications. While the Peer Reviewers' Openness Initiative (Morey et al., 2016) is campaigning for open data and materials (or an explanation of why making them available would be inappropriate) to be a minimum requirement before agreeing to review a paper (see https://opennessinitiative.org/) ${ }^{\mathrm{xi}}$. The BPS also updated its accreditation standards for undergraduate dissertations to ensure they accommodate open science projects where the study has been pre-registered before students' involvement (British Psychological Society, 2016) ${ }^{\mathrm{xii}}$.

Open Science offer important avenues for checking other researchers' analysis. There are ethical issues when participants' time and tax payers' money is spent on research projects, and so secondary analysis is a good use of the data produced from these resources. But QMiP are concerned that expectations to make data open as a mark of quality, could actually reduce the quality of qualitative research. For example, participants might be happy to share personal experiences with an individual researcher and trust them to treat their data with respect, but not want people they have not formed a relationship with accessing this data. This has real implications for limiting participation in psychological research.

The challenge for us is to make qualitative research issues visible by those making decisions about research practice. We can also learn from qualitative researchers who are exploring creative 
UK Qualitative Methods in Psychology (QMiP)

ways of doing Open Science. At the QMiP 2017 conference, for example, all three keynotes engaged in different ways with Open Science. Professor Carla Rice described her work facilitating activist art for social justice that included creating an archive of the artistic work (e.g. Rice,

Chandler, Harrison, Liddiard \& Ferrari, 2015) ${ }^{\text {xiii }}$, while extracts from the interviews Professor Celia Kitzinger conducted with friends and family of those who have experienced catastrophic brain injury were shared on healthtalk.org ${ }^{\text {xiv }}$ and also embedded in online versions of journal articles (Kitzinger \& Kitzinger, 2018). Their work offer examples of making research open in ways that creatively challenge realist notions of 'data', while Dr Pete Branney's keynote explored more nuanced ways of negotiating anonymity, confidentiality, and data sharing with participants than merely participating/not participating. That Open Science will impact on qualitative researchers was further shown when Branney was invited to a discussion panel at a recent BPS event on Open Science (Moving Psychological Science Forward, May 2018) to make sure qualitative methods were part of the conversation. Open Science is increasingly part of the research environment (see for example, https://www.scienceeurope.org/coalition-s/). It is therefore essential that qualitative researchers get involved in these conversations otherwise - like REF - we may be caught being asked to fulfil criteria more suited to quantitative methods.

3. Advances in psychology brought about by qualitative methods

Despite the challenges discussed above, UK qualitative researchers in psychology have much to celebrate, making significant contributions to psychology, particularly in the development of discourse analysis, interpretative phenomenological analysis and feminist informed research. We discuss these below, before highlighting where we see future exciting innovations in methods synthesising across epistemologies and disciplines and employing the affordances of digital technologies. 
UK Qualitative Methods in Psychology (QMiP)

We cannot discuss qualitative methods in UK based psychology without recognising the significant impact of feminist work. Indeed, we experience qualitative work as often associated with women and aligned with sexist dichotomies around male/female, rational/intuitive,

quantitative/qualitative, good/bad etc. So here is an opportunity for us to reclaim these associations and celebrate the determined move - often in the face of significant opposition or career risk - by British-based feminist researchers to do a different kind of psychology informed by a critical questioning of representation and knowledge in psychology. To name one is to not name the many, so instead we name a journal, Feminism \& Psychology. Feminism \& Psychology was established in 1991 and has since provided a place to publish high quality, important, feminist-informed qualitative research that identifies as psychological $^{\mathrm{xv}}$. It continues to do so, winning awards from the American Psychological Association, and pushing the boundaries of the English speaking academy to widen its perspective and hear from a range of marginalised voices in Psychology. As part of this commitment, its current editors seek to increase representation from those located in the global South and those using indigenous psychologies, as well as taking a pluralist and inclusive standpoint in recognising a range of feminisms (Macleod, Marecek \& Capdevila, 2014).

Feminism \& Psychology thus supports new ways of doing psychological work. In that sense it shares some of the aims of discourse analysis, which emerged in the 1980s as a seemingly unstoppable force in UK psychology. When considering psychological discourse analysis in the UK, three key texts from the 1980s stick out: Potter and Wetherell's (1987) Discourse Analysis: Beyond Attitudes and Behaviour; Ian Parker's (1992) Discourse Dynamics and Henriques et al.'s (1984) Changing the Subject. In different ways, each contributed important epistemological and methodological developments that subsequently expanded into a variety of forms of discourse analysis located along a continuum from poststructuralist theory to conversation analysis. Below, we give a flavour of this work by focusing on work by researchers to whom QMiP have given (or nominated for) awards or keynote invitations. 
As an example of poststructuralist discourse analysis, Rosalind Gill's work is outstanding, and the reason why QMiP nominated her for the 2017 BPS President's Award. With a PhD in Psychology, but rarely working in psychology departments, Gill developed a form of poststructuralist discourse analysis examining how cultural forms of sense-making circulating across the media have important implications for people's sense of self. She applies this signature style to illuminate a range of issues around work and labour, new technologies, inequality, media and gender, and intimacy and sexuality. For example, Gill developed the concept 'postfeminist sensibility', to describe how media hail young women as free, while linking freedom to disciplinary work on the self and body. Postfeminist sensibility subsequently informed a body of work by international scholars across a range of disciplines, including psychology, sociology, media and cultural studies; developing debates on the 'sexualisation of culture', new sexual subjectivities, intersectionality, agency, empowerment and neoliberalism (for the original paper and recent review and development papers see Gill, 2007, 2017; Riley et al., 2017).

Developing her theme of how apparently positive cultural discourses are psychologically harmful, Gill recently turned her analytical attention to resilience, arguing that like freedom, resilience is a concept being used to regulate people. For example, analysing a range of media texts, she and her co-author argued that at a time of austerity and growing inequalities people particularly middle class women - are called on to be resilient and use positive thinking to 'bounce back'. They argue that this psychological focus illegitimates social critique and demands for social transformation (Gill \& Orgad, 2018).

A more rhetorical discursive approach is exemplified by Stephen Gibson's discourse analysis performed on Milgram's obedience research, one of psychology’s most well-known studies (e.g. Gibson, 2013). Using archived data, Gibson's detailed analysis of the interactions between those involved in the study led him to claim that Milgram was not simply telling participants to continue with the study, but engaging in persuasive techniques. Gibson also showed that the 
participants often disobeyed the 'experimenter', and given that it was only the experimenter's final command, "you must continue", that looks like an order, Gibson concluded that this famous obedience study might not actually have been about obedience. We look forward to seeing if Gibson's keynote at the QMiP 2019 conference, co-hosted with the BPS History of Psychology Section, will further unsettle our taken for granted truths about Milgram's seminal study.

Taking a more conversation analytic approach to analysing talk, is Sarah Seymour Smith, our 2017 mid-career award winner. Seymour Smith (2013) applied discursive psychology techniques to critique previous assumptions that emotion talk in cancer forums is done by women. Her close attention to the sequential aspect of posts illustrated how men 'do' support through a number of discursive strategies that sanction emotional talk. Seymour-Smith's later research highlighted the need to design health interventions in collaboration with the communities they seek to serve. For example, her work with an African-Caribbean community pointed to the need for a mobile application for prostate cancer to address homophobic fears associated with the digital rectal examination in a culturally sensitive manner (e.g. Seymour-Smith et al, 2016).

Seymour Smith's work aligns with that of QMiP's 2018 President Award nominee, Elizabeth Stokoe, who developed the Conversation Analytic Role-play Method (CARM; www.carmtraining.org). As a technique for communication training, CARM is an exemplary form of applied qualitative research, used in training with a police Hostage Crisis Unit, the industrial reconciliation organisation ACAS, multinational companies, neighbourhood and community disputes; also with people with learning disabilities and with hospital receptionists. QMiP hopes to further support the application of discursive psychology by making work on the discursive constructions of migrants' part of a future BPS policy focus (Goodman et al., 2017).

Developing in parallel to the discursive moves in UK-based qualitative psychology were seismic shifts in phenomenology-informed qualitative methods, including Langridge's (e.g. 2007) critical narrative analysis, and King and Brooks' template analysis (e.g. Brooks et al, 2015). Most 
notably though, is the development of Interpretative Phenomenological Analysis (IPA), which formalised a procedure for analysing qualitative data to understand lived experience (e.g. Smith, Flowers \& Larkin, 2009). IPA's impact on psychological research is particularly significant in health psychology (see for example, Paul Flower's work on increasing HIV testing amongst vulnerable populations ${ }^{\mathrm{xvi}}$ ) and it is a method now taught to many undergraduate students as part of their psychology curriculum, evidenced in the UK qualitative text books that have IPA as a central method for UG training in qualitative methods (e.g. Smith, 2015; Sullivan \& Forrester, 2018).

Despite usually being considered separate fields of research, some UK researchers have sought to bring together insights from poststructuralist discursive and phenomenological qualitative analyses. Del Busso and Reavey (2011) for example, make an important case for including the embodied experience in poststructuralist informed research when trying to better understand women's experiences. Similarly, at the 2017 QMiP conference, Carla Willig and her postgraduates presented work offering different ways to bring Foucauldian Discourse Analysis and IPA together (Willig, Ledingham \& Baboulene, 2017), work linked to Willig's previous QMiP conference keynote and Bulletin article (Willig, 2016), which inspired further experimentation with synthesis (Black \& Riley, 2018). These moves represent a confidence, maturity and willingness to experiment that we see characterising contemporary qualitative methods in UK psychology. That much of this work was first published in the QMiP Bulletin and/or presented at QMiP conferences, points to the importance of QMiP in providing an organisational infrastructure that supports developments in qualitative research in psychology.

Other recent developments in qualitative research are seen in work exploring the affordances of new technologies. The ability to record naturally occurring conversations in real time; easily take and share photographs or videos; and interact with geographically dispersed others are just some of the ways that technology has fundamentally enabled developments in qualitative methods. Three-D printing and other ways of producing 'props' for research have also allowed creative innovations in 
methodology. For example, one study asked medical students to wear a temporary tattoo of a melanoma taken from a newly diagnosed patient in order to better understand a patient's lived experience (Corr et al., 2017). Dissemination practices are also greatly expanded, for example, the multi-disciplinary group of researchers at the Coma and Disorders of Consciousness Research Centre led by Celia and Jenny Kitzinger, used social media to live-report court proceedings; while their research generating knowledge on "the cultural, ethical, legal and social dimensions of coma, vegetative and minimally conscious states" (Coma and disorders of consciousness research centre, n.d.-2018) has been translated into accessible interactive information through poetry, visual arts, blogs, video, and discussion with lawyers and policy makers. Such work points to a radical departure in how we might 'do' qualitative research.

\section{Concluding comments}

As QMiP currently understands it, the key challenge for researchers using interpretivist qualitative methods is having to fit into systems of governance that are designed, in the most part, by and for quantitative researchers. We have sought to address these challenges through a variety of actions. Where we can, we leverage the power we have from being part of the BPS (for example, we have recently been grateful for BPS support in our lobbying around the Research Excellence Framework and supporting the production of the QMiP guidance for qualitative psychologists submitting to REF (Brooks et al., 2018a). This occurred through us building alliances with the BPS, a two way process, whereby we had to engage in what sometimes felt like exhausting continuous arguments for our case (at times it was like being the 'problem' student in the room - akin to Ahmed's (2014) discussion of being 'wilful subjects'). But equally, we were listened to by those with powers to act on our behalf in the BPS. We have also sought to build alliances with other organisations outside of the BPS and the UK, these will be even more essential as publication criteria become increasing linked to cross-country agreements. For example, nine European research councils have so far 
signed up to Open Access publishing www.scienceeurope.org/coalition-s. Open Access publishing means that people outside of the UK wanting to submit a paper to a UK based journal are likely to be asked to share their data; requiring them to have the resources to archive data (e.g. time to anonymise audio and video files, storage resources, previously negotiated ethical approval and consent for archiving data). We have noted some of the problems with Open Science for qualitative researchers above, but here we also acknowledge the possibility of it allowing deeper collaborations, as researchers start to register their planned studies and share their archived data.

While we have been outward looking, identifying threats and challenges to researchers using qualitative methods in psychology, we have also maintained an inward focus - understanding that QMiP represents a community of qualitative psychologists who need to share and develop their practice in innovative, nurturing and exiting ways. Thus, despite some very real concerns, particularly over the power of REF to fundamentally shape our discipline and push interpretative qualitative research out, we also have a lot to celebrate. What we discussed above, in terms of the cross disciplinary work, experiments with inter-epistemological methodologies, expanding affordances of new technologies, and developing centres of excellence with qualitative research methods at their heart, point to some of the exciting directions of UK qualitative research. At a time of widening divisions within societies, it feels good to conclude that QMiP is forming alliances, honouring community and providing support.

\section{References}

Ashworth, P. (2008). Conceptual foundations on qualitative psychology. In, Smith, J. (2015). (Ed.), Qualitative Psychology: A Practical Guide to Methods. London: Sage. $3^{\text {rd }}$ Edition.

Black, S. \& Riley, S. (2018). Active ink: Analysing the experience and construction of tattoos as therapy using dual-focus methodology. QMiP Bulletin, 25, 24-33. 
British Psychological Society. (n.d.-a). About us. Retrieved 11 June, 2018, from https://www.bps.org.uk/about-us

British Psychological Society. (n.d.-b). Member networks. Retrieved 11 June, 2018, from https://www.bps.org.uk/psychologists/member-networks

British Psychological Society. (2016). Standards for the accreditation of undergraduate, conversion and integrated Masters programmes in psychology. Leicester: BPS.

Branney, P., Witty, K., Braybrook, D., Bullen, K., White, A., \& Eardley, I. (2014). Masculinities, humour and care for penile cancer: A qualitative study. Journal of Advanced Nursing, 70(9), 2051-2060.

Brooks, J., King, N., Riley, S., Shaw, R. \& Willig, C. (2018a). Surviving and thriving REF2021 for qualitative psychologists: Discussion panel event at QMiP 2017 conference. QMiP Bulletin, 25, 29-33. https://shop.bps.org.uk/publications/qmip-bulletin-issue-25-spring-2018.html

Brooks, J., Goodman, S., Locke, A., Reavey, P., Riley, S. and Seymour-Smith, S. (2018b). Writing for the Research Excellence Framework 2021: Guidance for qualitative psychologists. Leicester: British Psychological Society.

Brooks, J. \& King, N. (2017). (Eds.). Applied Qualitative Research in Psychology. London: Palgrave.

Brooks, J., McCluskey, S., Turley, E. \& King, N. (2015). The utility of template analysis in qualitative psychology research. Qualitative Research in Psychology,12(2), 202-222. doi:10.1080/14780887.2014.955224

Carter, P., Chew, S., \& Sutton, E. (2018). Ethics in theory and pseudo-ethics in practice. In C. Macleod, J. Marx, P. Mnyaka, \& G. J. Treharne (Eds.), The Palgrave handbook of ethics in critical research (pp. 29-45). London: Palgrave-MacMillan. doi:10.1007/978-3-319-747217_3 
UK Qualitative Methods in Psychology (QMiP)

Coma and disorders of consciousness research centre. Retried from http://cdoc.org.uk/ $11^{\text {th }}$ June 2018.

Corr, M., Roulston, G., King, N., Dornan, T., Blease, C., \& Gormley, G. J. (2017). Living with 'melanoma'... for a day: A phenomenological analysis of medical students' simulated experiences. British Journal of Dermatology, 17, 771-778. doi:10.1111/bjd.15402

Cotton, D.R.E., Miller, W. \& Kneale, P. (2018). The Cinderella of academia: Is higher education pedagogic research undervalued in UK research assessment? Studies in Higher Education, 43(9),1625-1636. doi:10.1080/03075079.2016.1276549

Craig, P., Dieppe, P., Macintyre, S., Michie, S., Nazareth, I., Petticrew, M. et al. (2008).Developing and evaluating complex interventions: the new Medical Research Council guidance. British Medical Journal, 337, a1655.doi:10.1136/bmj.a1655

Del Busso, L. A., \& Reavey, P. (2013). Moving beyond the surface: A poststructuralist phenomenology of young women's embodied experiences in everyday life. Psychology and Sexuality, 4(1), 46-61. doi:10.1080/19419899.2011.589866

Economic \& Social Science Research Council. (2013). ESRC Open access to research outputs. London: ESRC.

Economic and Social Research Council. (2018). ESRC Research Data Policy. London: ESRC.

Finfgeld-Connett, D. (2016). The future of theory-generating meta-synthesis research. Qualitative Health Research, 26(3), 291-293.

Gibson, S. (2013). Milgram's obedience experiments: A rhetorical analysis. British Journal of Social Psychology, 52(2), 290-309.

Gibson, S., and Sullivan, C. (2018). A changing culture? Qualitative methods teaching in UK psychology. Qualitative Psychology, 5(2), 197-206. 
UK Qualitative Methods in Psychology (QMiP)

Gill, R. (2007). Postfeminist media culture: Elements of a sensibility. European Journal of Cultural Studies, 10(2), 147-166.

Gill, R. (2017). The affective, cultural and psychic life of postfeminism: A postfeminist sensibility 10 years on. European Journal of Cultural Studies, 20(6), 606-626.

Gill, R., \& Orgad, S. (2018). The amazing bounce-backable woman: Resilience and the psychological turn in neoliberalism. Sociological Research Online, 28(2), 477-495.

Goodman, S., Sirriyeh, A., \& McMahon, S. (2017). The evolving (re)categorisations of refugees throughout the 'Refugee/Migrant crisis'. Journal of Community and Applied Social Psychology, 27(2), 105-114. doi:10.1002/casp.2302

Gough, B., Hugh-Jones, S., \& Lawton, R. et al. (2002). Developing guidelines for the supervision of undergraduate qualitative research in psychology. LTSN/HEA Report. Available at tinyurl.com/q5gkmzj

Gough, B., \& Deatrick, J. A. (2015). Qualitative health psychology: Diversity, power and impact. Health Psychology, 34(4), 289-292. doi:10.1037/hea0000206

Greenhalgh, T., Annandale, E., Ashcroft, R., Barlow, J., Black, N., Bleakley, A., Boaden, R., Braithwaite, J., Britten, N., Carnevale, F., et al. (2016). An open letter to The BMJ editors on qualitative research. $B M J, 352$, i563.

Greenhalgh, T., \& Fahy, N. (2015). Research impact in the community based health sciences: An analysis of 162 case studies from the 2014 Research Excellence Framework. BMC Medicine, 13, 232.

Henriques, J., Hollway, Urwin, C. W., Venn, C., and Walkerdine, V. (1984). Changing the subject: Psychology, social regulation and subjectivity. London: Methuen.

Hunter, J. E. (2001). The Desperate Need for Replications. Journal of Consumer Research, 28(1), 149-158. 
Ioannidis, J. P. A. (2016). Why Most Clinical Research Is Not Useful. PLOS Medicine, 13(6), e1002049.

Kahneman, D. (2012). A proposal to deal with questions about priming effects. Retrieved from https://www.nature.com/polopoly_fs/7.6716.1349271308!/suppinfoFile/Kahneman\%20Lette r.pdf

Kitzinger, J., \& Kitzinger, C. (2018). Deaths after feeding-tube withdrawal from patients in vegetative and minimally conscious states: A qualitative study of family experience. Palliative Medicine, 32(7), 1180-1188.

Langdridge, D. (2007). Phenomenological psychology: Theory, research and method. Harlow: Prentice Hall.

Levelt, W. J., Drenth, P., \& Noort, E. (2012). Flawed science: The fraudulent research practices of social psychologist Diederik Stapel. Retrieved from https://www.tilburguniversity.edu/upload/3ff904d7-547b-40ae-85febea38e05a34a_Final\%20report\%20Flawed\%20Science.pdf

Macleod, C., Marecek, J., \& Capdevila, R. (2014). Feminism \& Psychology going forward. Feminism \& Psychology, 24(1), 3-17.

Macleod, C., Marx, J., Mnyaka, P., \& Treharne, G. J. (2018). Ethics in critical research: Stories from the field. In C. Macleod, J. Marx, P. Mnyaka, \& G. J. Treharne (Eds.), The Palgrave handbook of ethics in critical research (pp. 1-13). London: Palgrave-MacMillan.

Madill, A. (2015). Let a thousand flowers bloom. The Psychologist, 28, 656-658. https://thepsychologist.bps.org.uk/volume-28/august-2015/let-thousand-flowers-bloom

Madill, A. and Todd, K.Z. (2002). Proposal to the Council of the British Psychological Society for the formation of a new Section of the Society. Available at: https://www.academia.edu/1635472/Madill_A._Todd_K._Z._2002_._Proposal_to_the_Cou 
UK Qualitative Methods in Psychology (QMiP)

ncil_of_the_British_Psychological_Society_for_the_formation_of_a_new_Section_of_the_ Society_on_Qualitative_Methods_in_Psychology

Makel, M. C., Plucker, J. A., \& Hegarty, B. (2012). Replications in Psychology Research: How Often Do They Really Occur? Perspectives on Psychological Science, 7(6), 537-542. doi:10.1177/1745691612460688

Morey, R. D., Chambers, C. D., Etchells, P. J., Harris, C. R., Hoekstra, R., Lakens, D., ... Zwaan, R. A. (2016). The Peer Reviewers' Openness Initiative: Incentivizing open research practices through peer review. Royal Society Open Science, 3(1), 1-7. doi:10.1098/rsos.150547

Murphy, T. (2017). Revisiting the Research Excellence Framework: Ensuring quality in REF2021 or new challenges ahead? Perspectives, Policy and Practice in Higher Education, 21(1), 3439.

Neuroskeptic. (2012). The nine circles of scientific hell. Perspectives on Psychological Science, 7(6), 643-644.

Open Science Collaboration. (2015). Estimating the reproducibility of psychological science. Science, 349(6251), aac4716. doi:10.1126/science.aac4716

Parker, I. (1992). Discourse Dynamics: Critical Analysis for Social and Individual Psychology. London: Routledge.

Pashler, H., \& Wagenmakers, E. J. (2012). Editors' Introduction to the Special Section on Replicability in Psychological Science: A Crisis of Confidence? Perspectives on Psychological Science, 7(6), 528-530.

Potter, J. \& Wetherell, M. (1987). Discourse Analysis: Beyond Attitudes and Behaviour. London: Sage. 
UK Qualitative Methods in Psychology (QMiP)

Rapport, F., Storey, A., Porter, A., Snooks, H., Jones, K., Peconi, J., Sánchez, A., Siebert, S., Thorne, K., Clement, C. \& Russell, I. (2013). Qualitative research within trials: Developing a standard operating procedure for a clinical trials unit. Trials, 14(54), 1-8. Available online only doi:10.1186/1745-6215-14-54

Rice, C., Chandler, E., Harrison, E., Liddiard, K. \& Ferrari, M. (2015). Project Re•Vision: disability at the edges of representation. Disability and Society, 30 (4), 513-527.

Research Excellence Framework. (2017). What is the REF? Retrieved 11 June, 2018, from http://www.ref.ac.uk/about/whatref/

Riley, S. (2016). What does the Research Excellence Framework (REF) mean for qualitative psychologists? QMiP Bulletin, 21, 5-7.

Riley, S., Evans, A., Elliott, S., Rice, C. \& Marecek, J. (2017). A critical review of postfeminist sensibility. Social and Personality Psychology Compass, 11(12), e12367. Online first $\underline{\text { doi: } 10.1111 / \mathrm{spc} 3.12367}$

Saunders, B., Kitzinger, J., \& Kitzinger, C. (2015). Anonymising interview data: Challenges and compromise in practice. Qualitative Research, 15(5), 616-632.

Seymour-Smith, S. (2013). A reconsideration of the gendered mechanisms of support in online interactions about testicular implants: A discursive approach. Health Psychology, 32(1), 9199.

Seymour-Smith, S., Brown, D., Cosma, G., Shopland, N., Battersby, S. \& Burton, A. (2016). “Our people has got to come to terms with that": Changing perceptions of the digital rectal examination as a barrier to prostate cancer diagnosis in African-Caribbean men. PsychoOncology, 25(10), 1183-1190. 
UK Qualitative Methods in Psychology (QMiP)

Shaw, R. (2001). Why use interpretative phenomenological analysis in health psychology? Health Psychology Update, 10, 48-52.

Smith, J. (2015). (Ed.), Qualitative Psychology: A Practical Guide to Methods. London: Sage. $3^{\text {rd }}$ Edition.

Smith, J.A., Larkin, M., \& Flowers, P. (2009) Interpretative Phenomenological Analysis: Theory, method and research. London, Sage.

Statement of retraction. (2014). Ethnic and Racial Studies, 37(13), 2491.

Sullivan, C. \& Forrester, M. (Eds.) (2018). Doing qualitative research in psychology: A practical guide (2nd ed). London: Sage.

Sullivan, C., Gibson, S. \& Riley, S. (2012). Doing your qualitative psychology project. London: Sage.

Wiggins, S., Gordon-Finlayson, A., Becker, S., \& Sullivan, C. (2015). Qualitative undergraduate project supervision in psychology: Current practices and support needs of supervisors across North East England and Scotland. Qualitative Research in Psychology, 13(1), 1-19.

Willig, C. (2016). Constructivism and 'The Real World': Can they co-exist? QMiP Bulletin, 21, 3337.

Willig, C., Ledingham, S. \& Baboulene, K. (2017). Advancing dual focus methodology. Symposium at the Qualitative Methods in Psychology conference, 5-7 ${ }^{\text {th }}$ July, Aberystwyth University.

\footnotetext{
${ }^{\text {i }}$ Such as the ESRC Identities and Social Action Programme led by Margaret Wetherell, information and evaluation to be found at: https://www.researchcatalogue.esrc.ac.uk/grants/RES-065-27-0007/read and https://esrc.ukri.org/files/research/research-and-impact-evaluation/identities-and-social-action-programme/ ii The BPS was formed in 1901, and is now a registered charity acting as the central "representative body for psychology and psychologists in the UK", with responsibility for "the promotion of excellence and ethical practice in the science, education, and application of the discipline" (British Psychological Society, n.d.-a).

iii Our next conference is in 2019 in Cardiff, for details see www.bps.org.uk/events/qualitative-methods-psychologyhistory-philosophy-psychology-conference-2019 or follow \#qmip on twitter.
} 


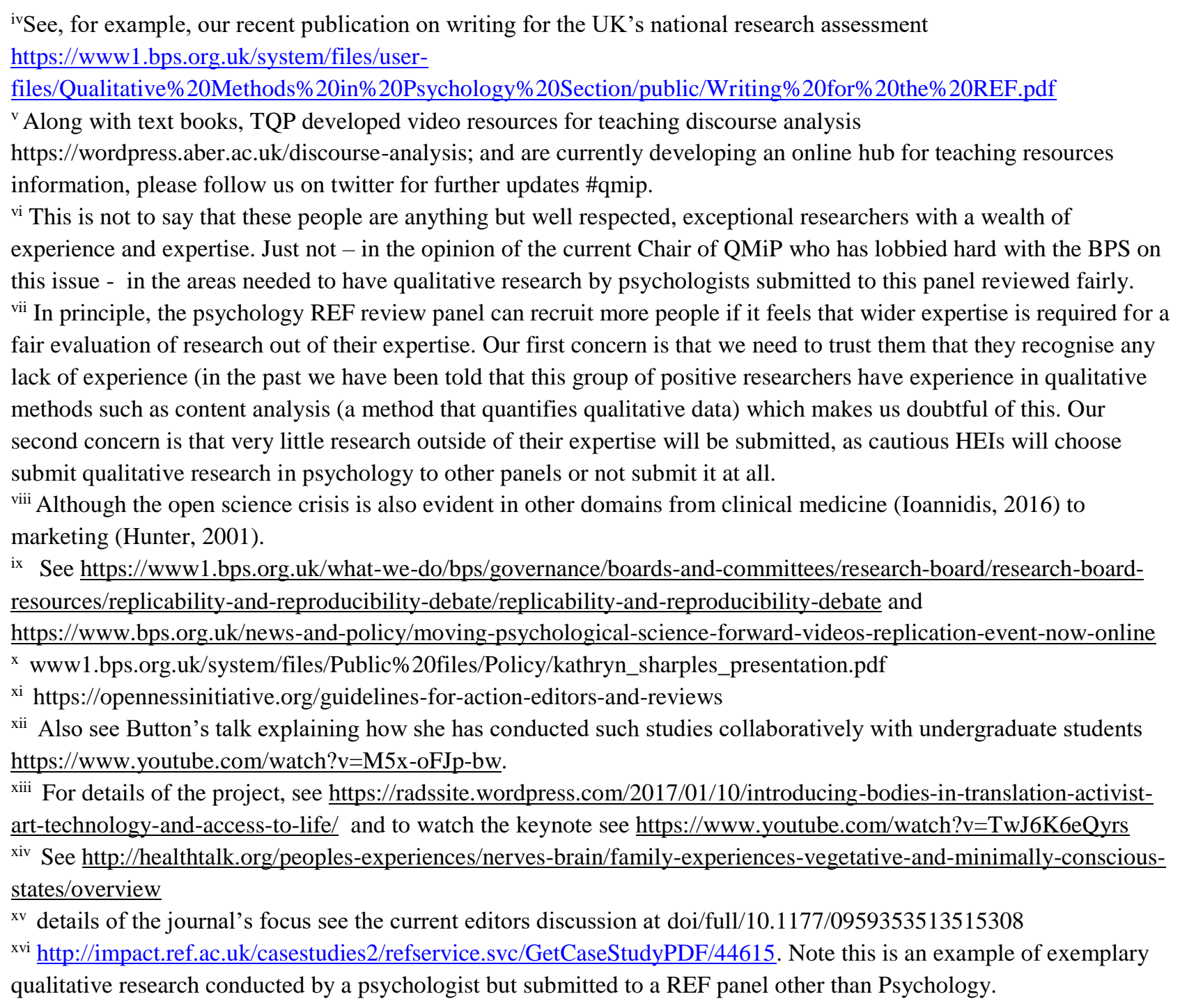

${ }^{\mathrm{iv}} \mathrm{See}$, for example, our recent publication on writing for the UK's national research assessment ttps://www1.bps.org.uk/system/files/useriles/Qualitative\%20Methods\%20in\%20Psychology\%20Section/public/Writing\%20for\%20the\%20REF.pdf

Along with text books, TQP developed video resources for teaching discourse analysis https://wordpress.aber.ac.uk/discourse-analysis; and are currently developing an online hub for teaching resources formation, please follow us on twitter for further updates \#qmip.

This is not to say that these people are anything but well respected, exceptional researchers with a wealth of experience and expertise. Just not - in the opinion of the current Chair of QMiP who has lobbied hard with the BPS on his issue - in the areas needed to have qualitative research by psychologists submitted to this panel reviewed fairly.

iii In principle, the psychology REF review panel can recruit more people if it feels that wider expertise is required for a air evaluation of research out of their expertise. Our first concern is that we need to trust them that they recognise any ack of experience (in the past we have been told that this group of positive researchers have experience in qualitative methods such as content analysis (a method that quantifies qualitative data) which makes us doubtful of this. Our submit qualitative research in psychology to other panels or not submit it at all.

viii Although the open science crisis is also evident in other domains from clinical medicine (Ioannidis, 2016) to marketing (Hunter, 2001).

ix See https://www1.bps.org.uk/what-we-do/bps/governance/boards-and-committees/research-board/research-boardresources/replicability-and-reproducibility-debate/replicability-and-reproducibility-debate and https://www.bps.org.uk/news-and-policy/moving-psychological-science-forward-videos-replication-event-now-online

${ }^{x}$ www1.bps.org.uk/system/files/Public\%20files/Policy/kathryn_sharples_presentation.pdf

${ }^{x i}$ https://opennessinitiative.org/guidelines-for-action-editors-and-reviews

xii Also see Button's talk explaining how she has conducted such studies collaboratively with undergraduate students https://www.youtube.com/watch?v=M5x-oFJp-bw.

xiii For details of the project, see https://radssite.wordpress.com/2017/01/10/introducing-bodies-in-translation-activistart-technology-and-access-to-life/ and to watch the keynote see https://www.youtube.com/watch?v=TwJ6K6eQyrs

xiv See http://healthtalk.org/peoples-experiences/nerves-brain/family-experiences-vegetative-and-minimally-consciousstates/overview

${ }^{x v}$ details of the journal's focus see the current editors discussion at doi/full/10.1177/0959353513515308

qualitative research conducted by a psychologist but submitted to a REF panel other than Psychology.

\section{Author biographies}

Sarah Riley is a Professor in Critical Health Psychology at Massey University, New Zealand, and a founding member of critical psychology research groups at both Bath and Aberystwyth Universities in the UK (https://ccpsy.wordpress.com). Her research uses qualitative methods to explore the psychological impact of neoliberalism, addressing questions of gender, embodiment, health, youth culture and citizenship. Her co-authored books include Critical Bodies (Palgrave/MacMillan, 2008), Doing Your Qualitative Research Project (Sage, 2012), Technologies of Sexiness: Sex, Identity and Consumer Culture (Oxford University Press, USA, 2014), Postfeminism and Health (Routledge, 2018) and Postfeminism and Body Image (Routledge, forthcoming). She has chaired the British Psychology Section 'Qualitative Methods in Psychology', is an international member for the Association of European Qualitative researchers in Psychology (EQuiP) and sits on the editorial boards of Feminism \& Psychology, Psychology \& Health, and Qualitative Research Methods in Psychology. Twitter: @ sarahrileybrown

Joanna Brooks is a Chartered Psychologist and a Lecturer in Psychology at the Manchester Centre for Health Psychology, University of Manchester. Her research focuses especially on the management and psychological impact of chronic and palliative illness conditions, and her work is 7 
informed by a particular interest in the development of novel and inclusive approaches to applied qualitative research. She is co-author (with Nigel King) of Applied Qualitative Research in Psychology (Palgrave, 2017); Template Analysis for Business and Management Students (Sage, 2017) and (with Nigel King and Christine Horrocks) of Interviews in Qualitative Research (Sage, forthcoming 2018, $2^{\text {nd }} \mathrm{Ed}$ ). She is a committee member and Chair Elect of the British Psychological Society's Qualitative Methods in Psychology section.

Dr Simon Goodman is a Research Fellow at Coventry University. His research uses discursive psychology to address a number of issues including the discursive construction of asylum seekers and refugees. His work focuses on what is, and what is not, considered to be racist particularly with regard to asylum seeking. His other interests include the British public's understanding of income inequality, the far right and political discourse.

Sharon Cahill is the Head of Department of Psychological Sciences, School of Psychology, University of East London. Sharon's research interests in the main involve exploring women's (and vulnerable peoples) experiences of life, mental health, emotions, work and the body using qualitative research methods. Recent peer-reviewed Journal articles include:

Moorley, C. R., Cahill, S. \& Corcoran, N. (2015) Life after stroke: Coping mechanisms among Caribbean women. Health and Social Care in the Community.doi:10.1111/hsc.12256

Gilbert, K., Tileaga, C., \& Cahill, S. (2014). Dilemmas of long-term unemployment: Talking about constraint, self determination and the future. International Journal of Education and Psychology in the Community. 4(1),7-33.

Peter Branney Senior Lecturer in Social Psychology at Bradford University and a Fellow of the British Psychological Society, Higher Education Academy and the Royal Society of Arts. He has undertaken a programme of award winning, internationally leading work exploring how men and women engage with healthcare, how they experience threats to their health, and how to improve their experience of healthcare. Dr. Branney co-authored the UK Department for Health report, 'The Gender \& Access to Services Study' and led the first national study of Patients' Experiences of Penile Cancer (PEPC), which is published on the award winning www.healthtalk.org and featured on BBC Radio 4's Inside Health, the BPS Impact Portal, and The Guardian newspaper. See for example, Branney, et al., (2014). Masculinities, humour and care for penile cancer: A qualitative study. Journal of Advanced Nursing, 70(9), 2051-2060.

Gareth Treharne is an Associate Professor in the Department of Psychology at the University of Otago in Aotearoa/New Zealand. He applies a range of critical methods to explore diverse issues in relation to health, disability, ethnicity, gender, and sexuality. He is a co-editor of The Palgrave Handbook of Ethics in Critical Research (2018) and a contributor to The SAGE Handbook of Qualitative Research Ethics (2018) and Qualitative Research in Clinical and Health Psychology (Palgrave MacMillan, 2015). Gareth is an Associate Fellow of the British Psychological Society and is a member of the committee of the 'Qualitative Methods in Psychology' section. Gareth is also a longstanding member of the International Society of Critical Health Psychology (www.ischp.net; @ crithealthpsych) and is the current Chair of the Society. Twitter: @ gjtreharne

Cath Sullivan is a Senior Lecturer in Psychology at the University of Central Lancashire, Preston, and her research interests are mainly focused on social psychology, gender, qualitative methods and mindfulness. Cath is currently the Honorary Secretary of the Qualitative Methods in Psychology section of the British Psychological Society and is a Senior Fellow of the Higher Education Academy. She is co-editor of two qualitative methods textbooks: Doing Qualitative Research in Psychology (SAGE, 2010, 2019) and Doing Your Qualitative Psychology Project (SAGE, 2012) 
UK Qualitative Methods in Psychology (QMiP)

and has recently published qualitative research on topics including mindfulness, work-life balance and lecturers' experiences of supervising qualitative dissertations. 